Vesna Tornjanski ${ }^{1}$, Dejan Petrović ${ }^{1}$, Sandra Nešić ${ }^{2}$

${ }^{1}$ University of Belgrade, Faculty of Organizational Sciences, Serbia ${ }^{2}$ Singidunum University, Faculty of Media and Communications, Serbia

\title{
Effectiveness of Knowledge Transfer Between Project Team Members in Digitally Disrupted Organizations
}

DOI: 10.7595/management.fon.2018.0034

Abstract:

Research question: The study aims to extend and deepen the understanding of maturity level of knowledge transfer effectiveness between project team members in an organization in which disruptive innovations and external forces foster acceleration of various types of changes within organization. Motivation / Idea: Banks in Serbia are characterized by dominant functional organizational structure in which knowledge is acquired and stored in well-established departments and branches. On the other hand, the banking sector in Serbia is going through transformation mainly due to external forces that accelerate significant changes, at the same time implying meaningful increase in number and types of projects which are becoming increasingly demanding and complex. These factors further imply a shift from functionally-based operations to project-based operations. A radical shift of temporary organization from functionally-oriented to project-oriented foster new challenges when knowledge transformation is in question. Accordingly, the purpose of this paper is to research predictors for knowledge transfer success between project teams and to reveal major barriers to knowledge transfer effectiveness in the banking sector. Data / Tools: This paper opted for a survey research method and the sampling frame includes 13 banks that operate in Serbia. Findings: Research results show that knowledge transformation between project team members is low. Moreover, very dynamic circumstances, projects complexity and tight deadlines create new challenges when knowledge transfer effectiveness is in question. Accordingly, research results show that organizational understanding, valuing and adequate support for knowledge acquisition and transfer represent significant indicators for knowledge transfer success within project teams in the banking industry of Serbia. Besides, individual readiness, efforts, capabilities and history of successful knowledge transfer play an important role in knowledge transformation success. Finally, regression analysis output disclosed that all observed aspects, i.e., characteristics of knowledge transfer, individual and organizational aspects represent significant simultaneous predictors for knowledge transfer success between project teams in the banking sector of Serbia. Contribution: The paper contributes to enriching the literature on knowledge transfer between project teams in an industry's, country's and regional contexts that have been poorly addressed so far. By focusing on this phenomenon, the paper contributes to project managers, strategic managers and policy makers by addressing the gap between importance of knowledge transfer in one hand, and poor project outcomes on the other.

Keywords: Knowledge transfer effectiveness, banking industry, digital disruption, empirical research, project success

JEL Classification: G21, O22, D83

\section{Introduction}

The banking sector in Serbia faces unprecedented challenges imposed by the fourth industrial revolution, strong competition, frequent structural, regulatory and technological developments, economic crisis and iterative customers' requirements. These underlying influences have intensified initiation and implementation of various changes through projects within banks, of which the most prominent are IT based (Tornjanski et al., 2017a).

As more and more sectors adopt a project-based mode of operation, project journey acquires accelerated significance within organizations and management science nowadays. Projects are defined as organizations, created with specific aim and scope and built upon predefined and definite periods of time (Gann and Salter, 1998; Turner and Muller, 2003; Cacciatori et al., 2012; Todorovic et al., 2015). Many authors (e.g., 
Markus and Benjamin, 1996; Turner et al., 1996; Markus, 2004; Peppard et al., 2007; Crawford and Nahmias, 2010) have recognized that projects can be significant drivers of change within organizations, having principal dependency on information technologies and knowledge as a strategic resource (Mehta et al., 2014).

Knowledge represents a vital invisible organizational value that creates individuals and contributes to improvement of firm's competitive advantage (Drucker, 1993). A knowledge-based perspective of an organization has emerged in the literature of strategic management and extends the resource-based theory (Alavi and Leidner, 2001). The importance of knowledge, its way of acquiring, using and sharing, is widely accepted as key to project and organizational performances, respectively (Prusak, 2015). Zhao et al. (2015) argue that effective knowledge transfer exerts a positive outcome on project efficiency, effectiveness and improved quality of services. However, due to temporary nature of projects, collecting and transferring knowledge is more difficult in project-type operations than in continuous operations (Cacciatori et al., 2012). Despite the relevance that knowledge transfer phenomenon has on an overall project performance, McKinsey and the University of Oxford revealed that large IT projects exceed budget by $45 \%$, break the schedule plan by $7 \%$, and deliver $56 \%$ less business value than expected (Bloch et al., 2012). Similarly, research results from the Chaos Manifesto of 2013, show that only 39\% of worldwide IT projects achieved project management success (The Standish Group International, 2013).

Taking into account an evident gap between importance of knowledge transfer, on one hand, and poor project outcomes on the other, effectiveness of knowledge transfer in project adventure remains to be a challenging task that requires deeper understanding and research. Moreover, little is known about effects of knowledge transfer in banking - the industry that is in a revolutionary transfer process. Accordingly, for both practical and theoretical reasons, this study is developed to research the effectiveness of knowledge transfer between project team members in digitally disrupted organizations. The purpose of this study is to clarify the biggest challenges of effective knowledge transfer during project journeys in banks that operate in Serbia.

The paper is organised as follows. The literature review section unfolds an overview of the industry under study and exhibits the backgrounds of knowledge transfer among project team members. The research method is then introduced with a detailed explanation of the steps, measures and a sample. Afterwards, the results and discussion of the study are presented. Finally, the paper concludes with the implications and recommendations to practice, along with the suggestions for future research.

\section{Literature Review}

\subsection{An overview of the industry under study}

The banking sector of Serbia has experienced significant transfer in past decades. The 1990s were characterized by political instability, hyperinflation and collapse of the financial service sector. However, at the beginning of the 21 st century, the banking sector of Serbia has begun to recover due to structural economic reforms and has taken restructuring measures that resulted in a significant level of the sector's stability. With the wave of privatization, liberalization and consolidation, considerable developments have been made in the banking industry. These efforts were recognized as key elements of successful transition towards a system that is market-oriented, attributing to a more efficient and well-functioning sector (Barisitz and Gardo, 2008; Sokic, 2015). Since 2008, the global economic crisis has caused structural weaknesses of the banking sector that led to the recession in 2009. Macroeconomic volatility, fast-changing and unpredictable business environment represent crucial issues that banksare still struggling against aiming for further growth. Moreover, a high level of competition between 30 active banks, technology and digital innovations, heterogeneity of customers' needs and shortened product life cycles have imposed additional challenges to banks, signifying continuous change of their strategic focus and competitive dynamics (NBS, 2016; Tornjanski et al., 2017; Tornjanski et al., 2017a). In the era of the fourth industrial revolution, the banking sector of Serbia is at the beginning of a new journey, strengthened to find a perfect equilibrium between all influential factors that disturb the banking business, of which the most challenging are: harmonization between regulatory requirements, intensified changes in customers' needs and evolving digital disruption (Tornjanski et al., 2017a). In such circumstances, projects represent important vehicles for all organizational changes, particularly those that are based on information technologies.

\subsection{Knowledge transfer between project team members}

According to Kirchner \& Cudanov (2011), knowledge-intensive organizations are characterized by a quick change and involvement of many employees that are pursuing different business activities. In such organizations, knowledge is recognized as diverse; with vast proportions that steadily grow. Hence, the distribution of knowledge between project team members, individuals and communities of practices is viewed as 
an important factor. According to Stevens and Campion (1994), an overall capability of a team to harmonize knowledge and skills of its members is considered as a basic principle for successful accomplishment of team work. Furthermore, capabilities of project teams of managing and exploiting knowledge have been certified to play a weighty function in executing projects (Teerajetgul et al., 2009). Most studies have adopted knowledge transfer as a process that consists of two sub-processes, i.e., sending knowledge and receiving knowledge (Ko et al., 2005; Zhao et al., 2015). Other scholars see knowledge flows as "knowledge as a solution", "knowledge as experience" and "socially created knowledge" (Snider and Nissen, 2003; Ajmal and Koskinen, 2008). One of the definitions of knowledge transfer states that knowledge transfer is: "the methodical replication of the expertise, wisdom, insight, and tacit knowledge of key professionals into the heads and hands of their co-workers. It is more than just on-the-job training. In organizational theory, knowledge transfer is the practical problem of transferring knowledge from one part of the organization to another. Knowledge transfer seeks to organize, create, capture, or distribute the "know-how" of the most expert in a field and ensure its availability for future stakeholders" (Howlett et al., 2011; Prusak, 2015, p.6).

Other authors outline knowledge transfer as "the process by which one unit of an organization, such as a group or department, is affected by the experience of another" (Argote and Ingram, 2000, p.151). According to Zhao et al. (2015), cross-project knowledge transfer is viewed as "the communication activities of knowledge from a source project to a recipient project so that the useful knowledge is absorbed and reused by the recipient project".

Based on the thematic analysis carried out by Broadley et al. (2016), authors argue that nuanced range of tools, techniques and methods can strengthen the multidisciplinary engagement and can create a shift from co-design methods to sustain collaborative mindsets in knowledge swap toward innovation. When innovation is in question, cross-boundary teaming is viewed as an increasingly popular strategy for innovation. According to the authors, knowledge diversity represents an asset to extend the range of views and ideas that teams can use to innovate (Edmondson et al., 2018). To enhance the capacity of a project team to innovate and manage information, Huang and Chin (2018) suggest adoption of collective teaching to create team intelligence. Moreover, results from the research study taken by Prieto-Pastor et al. (2018) show that knowledge integration represents a benefit for exploratory and exploitive learning, implying that R\&D organizations may be ambidextrous in managing knowledge.

Several studies have been conducted to identify and clarify a set of factors that disturb effective cross-project knowledge transfer at both organizational and individual levels. According to Bakker et al. (2011), there are five factors, i.e., relational embeddedness, cognitive embeddedness, temporal embeddedness, absorptive capacity and motivation that represent forceful predictors of the degree of project knowledge transfer. Lewis et al. (2005) note that project task similarity is the precondition for effective knowledge transfer. On the other hand, Park et al. (2008) point out that time urgency needed for project completion is an important factor for a successful knowledge transfer among project team members (Zhao et al., 2015). De Long and Fahey (2000) have found that organizational culture plays an important role in knowledge origination, exchange, and purposive utilization. In addition to this, Naftanaila (2010) notes that flat organizational culture and decentralized decision-making support knowledge transfer among project team members. Besides, Naftanaila (2010) point out that management style, trust, motivation and values can also influence knowledge flows among project team members.

Banks in Serbia are characterized by functional organizational structure. According to Ajmal and Koskinen (2008), in functional organizations, knowledge is acquired and stored in well-established departments and branches. In such organizations, project teams can easily access and use documented records of knowledge. On the other hand, the banking sector in Serbia is going through transformation mainly due to external forces that accelerate significant changes, at the same time implying meaningful increase in the number and types of projects which are becoming increasingly demanding and complex, and should be implemented within very tight deadlines.

With that in mind, in this study we hypothesize:

H1: Knowledge transfer is at a low level of effectiveness among project team members in the banking industry in Serbia.

H2: Knowledge complexity and difficulty to codify knowledge linearly increase the difficulty to transform knowledge among project team members in banks in Serbia and at the same time decrease the success of knowledge transfer.

H3: Organizational understanding, valuing and adequate support for knowledge acquisition and transfer are in a positive correlation with effective knowledge transfer between project teams in the banking industry of Serbia. 
H4: Individual readiness, efforts, capabilities and a history of successful knowledge transfer are in a positive correlation with the success of knowledge transfer between project team members in the banks in Serbia. H5: Organizational and individual efforts in a simultaneous loop with the characteristics' levels of knowledge transfer are predictors for knowledge transfer success among project team members in the banking sector of Serbia.

\section{Research Methods}

This paper opted for a survey research method. Based on the broader literature review (e.g. Argote and Ingram, 2000; Cowan et al., 2000; Haldin-Herrgard, 2000; Rivkin, 2001; Beesley, 2004; Ajmal and Koskinen, 2008; Szulanski et al., 2016), a web-based questionnaire with a five-point scale is employed as a survey instrument. During the survey development, all required methodological principles were met (Saris and Gallhofer, 2014).

The questionnaire contains 20 questions that are clustered in 5 main sections. The first section consists of enquiries in regard to gender, age, education, position in the company, years of overall and current work experience, the company's name and the role of participant in the project. The second part of the questionnaire aims to research into how project team members perceive the following characteristics levels of knowledge: level of difficulty to codify knowledge, level of knowledge complexity and level of difficulty to transfer knowledge. The next set of questions refer to individual experience in relation to knowledge transfer among project team members: readiness, capability to transform knowledge and the history of successful knowledge transfer. The fourth section deals with the organizational aspect: the level of understanding the importance of knowledge transfer, the degree to which the organization recognizes and values participants of project team who share their knowledge and the level of providing adequate support in acquiring and transforming knowledge during the project journey. The last part of the questionnaire aims to measure the effectiveness of knowledge transfer in cross-functional team members and those that have the same role in the project. The final question aims to reveal what are the major barriers for effective knowledge transfer among project team members.

Our sampling frame includes experts who had one of the three conventional roles in a project team, i.e., leader, member or contributor. A web-based questionnaire was sent via e-mail to 150 project experts who are employed in banks that operate in Serbia. Of the 150 experts who are invited to participate in the survey, 54 completed the questionnaire; yielding a response rate of $36 \%$. The banking sector was selected for the sake of the following reasons. First, the banking sector in Serbia plays a key role in the financial system stability of the country. Second, the banking industry is recognized as one of the most disruptive industries nowadays. Finally, the disruptive innovations and external forces foster acceleration of various types of changes which imply a significant increase in the number of projects and their complexity. Very dynamic circumstances, projects complexity and tight deadlines create serious challenge for effective knowledge transfer to all stakeholder groups. From 30 active banks that operate in Serbia, 13 banks were involved in the study. The list of banks which contributed to the research is presented in Table 1.

Table 1: The list of banks included in the study

\begin{tabular}{|l|c|c|}
\hline \multicolumn{1}{|c|}{ Company name } & N & Percent \\
\hline Addiko bank & 2 & $4 \%$ \\
\hline AlK bank & 4 & $7 \%$ \\
\hline Alpha bank & 4 & $7 \%$ \\
\hline Erste bank & 5 & $9 \%$ \\
\hline Eurobank & 8 & $15 \%$ \\
\hline Intesa bank & 5 & $9 \%$ \\
\hline Komercijalna banka & 6 & $11 \%$ \\
\hline NLB bank & 3 & $6 \%$ \\
\hline Raiffaisen bank & 3 & $6 \%$ \\
\hline Sberbank & 4 & $7 \%$ \\
\hline Telenor bank & 3 & $6 \%$ \\
\hline Unicredit bank & 4 & $7 \%$ \\
\hline Vojvodjanska banka & 3 & $6 \%$ \\
\hline Total & $\mathbf{5 4}$ & $\mathbf{1 0 0} \%$ \\
\hline
\end{tabular}

Source: Authors 
Finally, data were analyzed in three main phases using SPSS software package. Our analysis of the data started from descriptive statistics to present a summary of collected data and to test one hypothesis. The second phase of the data analysis encompasses the assessment of distribution normality. Normal distribution is tested utilizing the Kolmogorov-Smirnov test. Next, to assess the strength of the relationship in a monotonic relationship between variables, Spearman's rank correlation coefficient is carried out, followed by a regression analysis to estimate the relationships among dependent and independent variables in the model. Finally, frequencies were used to reveal the major barriers for effective knowledge transfer among project team members in the banking sector of Serbia.

\section{Results and Discussion}

The first two phases of data analysis refer to summarizing the data and testing the normal distribution. The results are shown in Table 2.

Table 2: Descriptive statistics and Kolmogorov-Smirnov test of normal distribution

\begin{tabular}{|c|c|c|c|c|c|c|}
\hline $\begin{array}{l}\text { Grouped } \\
\text { variables }\end{array}$ & Variables & $\mathbf{N}$ & Minimum & Maximum & Mean & Std. Deviation \\
\hline \multirow{3}{*}{$\begin{array}{l}\text { General } \\
\text { information }\end{array}$} & Age & 54 & 22.0 & 50.0 & 33.278 & 71.200 \\
\hline & Work experience in total & 54 & .0 & 25.0 & 7.907 & 66.176 \\
\hline & $\begin{array}{l}\text { Work experience on current } \\
\text { position }\end{array}$ & 54 & .0 & 18.0 & 3.843 & 42.000 \\
\hline \multirow{3}{*}{$\begin{array}{l}\text { Characteristics } \\
\text { of knowledge } \\
\text { transfer }\end{array}$} & $\begin{array}{l}\text { Level of difficulty to codify } \\
\text { knowledge }\end{array}$ & 54 & 1.0 & 5.0 & 3.630 & 14.575 \\
\hline & Level of knowledge complexity & 54 & 1.0 & 5.0 & 3.741 & 14.033 \\
\hline & $\begin{array}{l}\text { Level of difficulty to transfer } \\
\text { knowledge }\end{array}$ & 54 & 1.0 & 5.0 & 3.574 & 14.354 \\
\hline \multirow{3}{*}{$\begin{array}{l}\text { Individual } \\
\text { aspect }\end{array}$} & $\begin{array}{l}\text { I am willing to share knowledge to } \\
\text { project team members }\end{array}$ & 54 & 1.0 & 5.0 & 3.593 & 13.943 \\
\hline & $\begin{array}{l}\text { I make an effort. I have the ability } \\
\text { and I am capable of transferring } \\
\text { knowledge }\end{array}$ & 54 & 1.0 & 5.0 & 3.333 & 14.537 \\
\hline & $\begin{array}{l}\text { I have a history of successful } \\
\text { knowledge transfers }\end{array}$ & 54 & 1.0 & 5.0 & 2.463 & 12.546 \\
\hline \multirow{3}{*}{$\begin{array}{l}\text { Organizational } \\
\text { aspect }\end{array}$} & $\begin{array}{l}\text { Organization fully understands the } \\
\text { importance of knowledge transfer it } \\
\text { requires from each project member }\end{array}$ & 54 & 1.0 & 5.0 & 3.037 & 11.969 \\
\hline & $\begin{array}{l}\text { Organization recognizes and } \\
\text { values participants of project team } \\
\text { who share their knowledge }\end{array}$ & 54 & 1.0 & 5.0 & 2.759 & 13.864 \\
\hline & $\begin{array}{l}\text { Organization provides adequate } \\
\text { acquiring and transfer of } \\
\text { knowledge during the project }\end{array}$ & 54 & 1.0 & 5.0 & 2.722 & 13.517 \\
\hline \multirow{2}{*}{$\begin{array}{l}\text { Knowledge } \\
\text { transfer } \\
\text { effectiveness }\end{array}$} & $\begin{array}{l}\text { Knowledge transfer is the most } \\
\text { effective between cross-functional } \\
\text { project team members }\end{array}$ & 54 & 1.0 & 5.0 & 2.722 & 13.377 \\
\hline & $\begin{array}{l}\text { Knowledge transfer is the most } \\
\text { effective between participants who } \\
\text { have the same role in project }\end{array}$ & 54 & 1.0 & 5.0 & 2.907 & 14.955 \\
\hline Total & Valid N (list wise) & 54 & & & & \\
\hline
\end{tabular}

Source: Authors

Based on the results presented in Table 2, respondents in this research are 33 years old on an average, have almost 8 years of work experience and almost 4 years of work experience at the current position.

Participants included in the study have estimated characteristics of knowledge transfer, variables with respect to individual and organizational aspect when knowledge transferring is in question, and finally have assessed the success of knowledge transfer among project team members using Likert scale from 1 to 5 . 
Comparing mean values between grouped variables, respondents have assessed that the difficulty to transfer and codify knowledge and its complexity during the project journey have greater weights $(m=3.648)$ than variables that relate to individual $(m=3.130)$ and organizational aspects $(m=2.839)$. The smallest mean value refers to knowledge transfer effectiveness among project team members that have the same role in the project and between cross-functional team members $(m=2.815)$. Accordingly, hypothesis 1 is supported.

In regard to the distribution normality evaluation, the results of Kolmogorov-Smirnov test show that for a majority of variables normal distribution does not exist $(p<0.05)$. Hence, hypotheses 2.3 and 4 were tested using Spearman's rho correlation. Table 3 provides an insight into the correlation analysis output.

Table 3: Spearman's rho correlation matrix

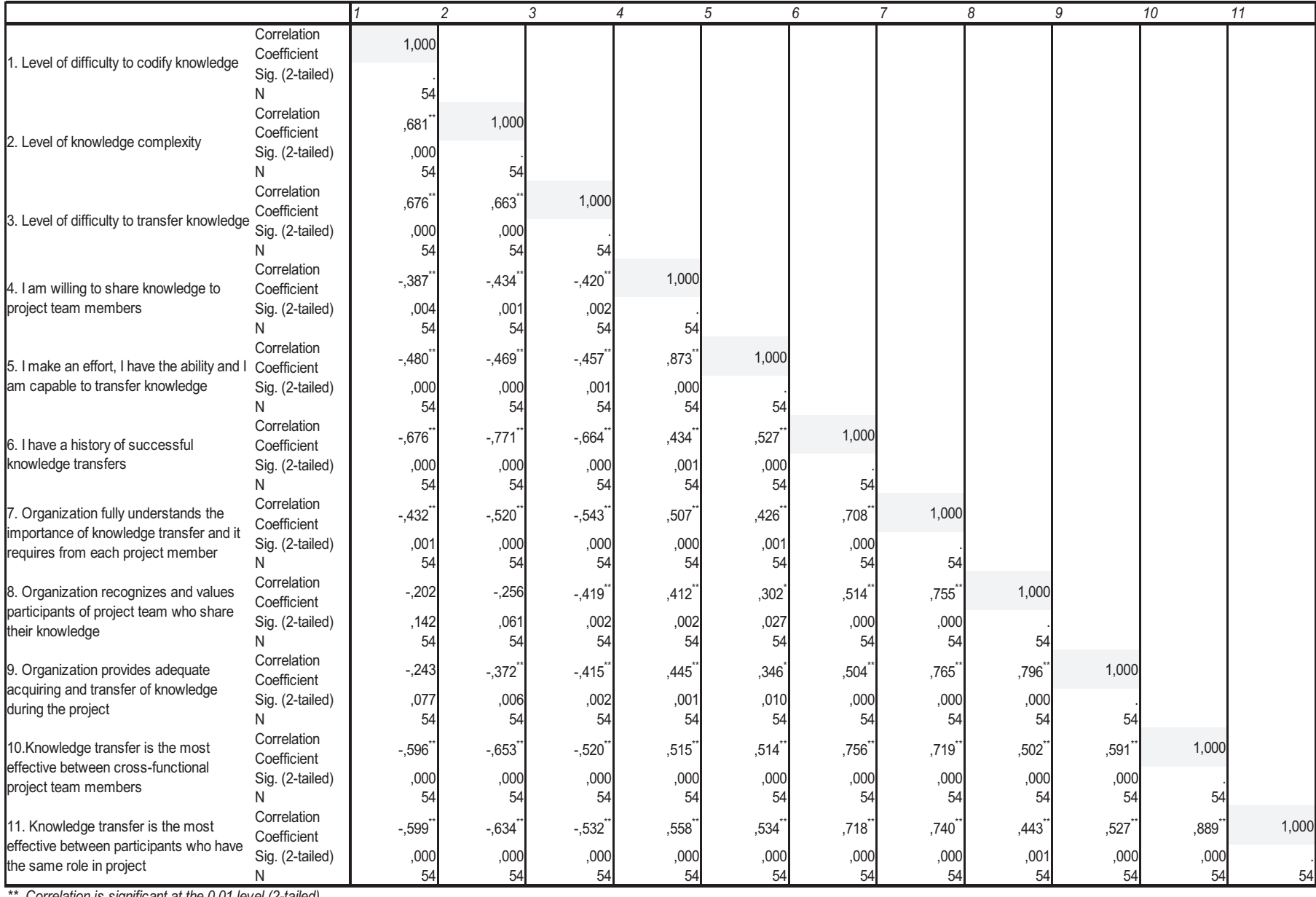

* Correlation is significant at the 0.05 level (2-aile

\section{Source: Authors}

According to the results, knowledge complexity is in a moderate uphill correlation with the difficulty to transfer knowledge $(r=0.663 ; p=0.000)$. Similarly, the difficulty to transfer knowledge is in a moderate positive relationship with the difficulty to codify knowledge $(r=0.676 ; p=0.000)$. On the other hand. knowledge complexity is in a moderate downhill correlation with the knowledge effectiveness between both cross functional project team members $(r=-0.653 ; p=0.000)$ and between members with the same role in project $(r=-0.634 ; p=0.000)$. Similarly, knowledge transfer difficulty $(r=-0.520 ; p=0.000 ; r=-0.532 ; p=0.000)$ and codification difficulties $(r=-$ $0.596 ; p=0.000 ; r=-0.599 ; p=0.000$ ) are in a moderate negative relationship with the knowledge effectiveness for both observed groups: teams with the same role in project and cross-functional team members.

In other words, when a project complexity rises, knowledge transferring is becoming linearly difficult. Furthermore, when knowledge is difficult to transfer, it is also difficult to codify. To the contrary, when knowledge complexity, difficulties to transfer and codify knowledge increase, knowledge transfer effectiveness decreases for both project team members in the same project role and for cross-functional project team members in the banking sector of Serbia. Accordingly, hypothesis 2 is supported. 
With regard to hypothesis 3, we have examined the relationship between groups of variables that relate to organizational context and knowledge transfer success. Based on the obtained results, organizational understanding of knowledge transfer importance required from each project team members is in a strong positive linear relationship with knowledge transfer effectiveness for both observed groups. i.e., cross-functional project teams $(r=0.719 ; p=0.000)$ and members in the same project task $(r=0.740 ; p=0.000)$. Organizational recognition and valuing of project team members who share knowledge is in an uphill moderate linear correlation with the effectiveness of knowledge transfer between cross-functional team members $(r=0.502$; $p=0.000$ ) and in a weak positive relationship with the effectiveness of knowledge transfer within teams with the same project role $(r=0.443 ; p=0.001)$. Organizational support for adequate acquiring and transfer of knowledge during the project is in a moderate uphill relationship with knowledge success between crossfunctional teams $(r=0.591 ; p=0.000)$ and between groups of experts with the same role in the project $(r=0.527 ; p=0.000)$. That is to say, the presented results indicate that the organizational aspect represents a significant indicator for knowledge transfer success within project teams in the banking industry of Serbia. Therefore hypothesis 3 is supported.

Hypothesis 4 is tested using correlation analysis too. Individual readiness to share knowledge is in a moderate positive relationship with the knowledge transfer success between cross-functional team members $(r=0.515 ; p=0.000)$ and among individuals in the same team $(r=0.558 ; p=0.000)$. Also, an individual's efforts and capabilities of transferring knowledge are in a moderate uphill relationship with the effectiveness of knowledge transfer for both observed groups, cross-functional teams $(r=0.514 ; p=0.000)$ and members of the same team $(r=0.534 ; p=0.000)$. The history of successful knowledge transfer is in a strong positive correlation with the knowledge transfer success according to the correlation coefficients for both cross-functional groups $(0.756 ; p=0.000)$ and among members within one team $(0.718 ; p=0.000)$. Accordingly, hypothesis 4 is supported.

With respect to hypothesis 5 , we have estimated the relationships among dependent and independent variables. Independent variables in the model represent all variables from 1 to 9 in Table 3, i.e., a group of variables referring to knowledge transfer characteristics, variables that relate to individual and organizational aspects. On the other hand, knowledge success, i.e., variables from 10 to 11 in Table 3 are padded as dependent variables in the model. The model summary is shown in Table 4.

Table 4: Regression Model Summary

\begin{tabular}{|c|c|r|r|r|}
\hline Model & $\mathbf{R}$ & R Square & Adjusted R Square & Std. Error of the Estimate \\
\hline 1 & 0.853 & 0.727 & 0.672 & 0.572995 \\
\hline
\end{tabular}

Source: Authors

Based on the output presented in Table $4\left(R^{2}=0.727 ; R^{2} a d j=0.672\right), 72.7 \%$ of all variables are explained by knowledge transfer success. The following table (Table 5) shows the ANOVA analysis results in regard to the regression model.

Table 5: ANOVA analysis

\begin{tabular}{|c|l|r|r|r|r|r|}
\hline \multicolumn{2}{|c|}{ Model } & Sum of Squares & df & Mean Square & F & Sig. \\
\hline \multirow{3}{*}{1} & Regression & 38.554 & 9 & 4.284 & 13.047 & .000 \\
\cline { 2 - 7 } & Residual & 14.446 & 44 & 0.328 & & \\
\cline { 2 - 7 } & Total & $\mathbf{5 4}$ & $\mathbf{5 4}$ & & & \\
\hline
\end{tabular}

Source: Authors

The ANOVA analysis has resulted in F statistics of 13.047 and significance of $p<0.001$, meaning that all predictors statistically significantly predict the effectiveness of knowledge transfer.

The following results from the regression analysis, organizational and individual efforts in simultaneous loop with the characteristics levels of knowledge transfer represent significant predictors for knowledge transfer success among project team members in the banking sector of Serbia. Accordingly, hypothesis 5 is supported.

The table below (Table 6) depicts coefficients for each constent variable in the model. According to the results shown in Table 6, the most important predictor for successful knowledge transfer among project team members in the banking sector of Serbia refers to organizational aspect. More precisely, organizational full 
understanding of importance of knowledge transfer and organizational requirement for knowledge transfer from each project team member is the most significant predictor $(p=0.008)$ of an effective knowledge transfer among project teams in the banking industry. On the contrary, the least important predictor for effective knowledge transfer is a knowledge transfer difficulty $(p=0.577)$.

Table 6: Coefficients for constant variables in the regression model

\begin{tabular}{|c|c|c|c|c|c|c|}
\hline & \multirow{2}{*}{ Model } & \multicolumn{2}{|c|}{$\begin{array}{l}\text { Unstandardized } \\
\text { Coefficients }\end{array}$} & \multirow{2}{*}{$\begin{array}{c}\text { Standardized } \\
\text { Coefficients } \\
\text { Beta }\end{array}$} & \multirow{2}{*}{$t$} & \multirow{2}{*}{ Sig. } \\
\hline & & B & $\begin{array}{l}\text { Std. } \\
\text { Error }\end{array}$ & & & \\
\hline \multirow{10}{*}{1} & (Constant) & 0.0000 & 0.078 & & 0.000 & 1.000 \\
\hline & $\begin{array}{l}\text { Level of difficulty to codify } \\
\text { knowledge_transformed }\end{array}$ & -0.228 & 0.153 & -0.228 & -1.49 & 0.143 \\
\hline & $\begin{array}{l}\text { Level of knowledge } \\
\text { complexity_transformed }\end{array}$ & -0.097 & 0.172 & -0.097 & -0.562 & 0.577 \\
\hline & $\begin{array}{l}\text { Level of difficulty to transfer } \\
\text { knowledge_transformed }\end{array}$ & 0.18 & 0.142 & 0.18 & 1271.000 & 0.211 \\
\hline & $\begin{array}{l}\text { I am willing to share knowledge to } \\
\text { project team members transformed }\end{array}$ & 0.093 & 0.197 & 0.093 & 0.471 & 0.64 \\
\hline & $\begin{array}{l}\text { I make an effort. I have the ability and } \\
\text { I am capable of transferring } \\
\text { knowledge transformed }\end{array}$ & 0.074 & 0.193 & 0.074 & 0.384 & 0.703 \\
\hline & $\begin{array}{l}\text { I have a history of successful } \\
\text { knowledge transfers_transformed }\end{array}$ & 0.271 & 0.191 & 0.271 & 1.42 & 0.163 \\
\hline & $\begin{array}{l}\text { Organization fully understands the } \\
\text { importance of knowledge transfer and } \\
\text { it requires from each project member } \\
\text { to be transformed }\end{array}$ & 0.442 & 0.159 & 0.442 & 2784.000 & 0.008 \\
\hline & $\begin{array}{l}\text { Organization recognizes and values } \\
\text { participants of project team who share } \\
\text { their knowledge transformed }\end{array}$ & -0.147 & 0.159 & -0.147 & -0.923 & 0.361 \\
\hline & $\begin{array}{l}\text { Organization provides adequate } \\
\text { acquiring and transfer of knowledge } \\
\text { during the project transformed }\end{array}$ & 0.113 & 0.148 & 0.113 & 0.764 & 0.449 \\
\hline
\end{tabular}

Source: Authors

The results are presented in Figure 1. too.

Figure 1: Predictor importance for knowledge transfer success

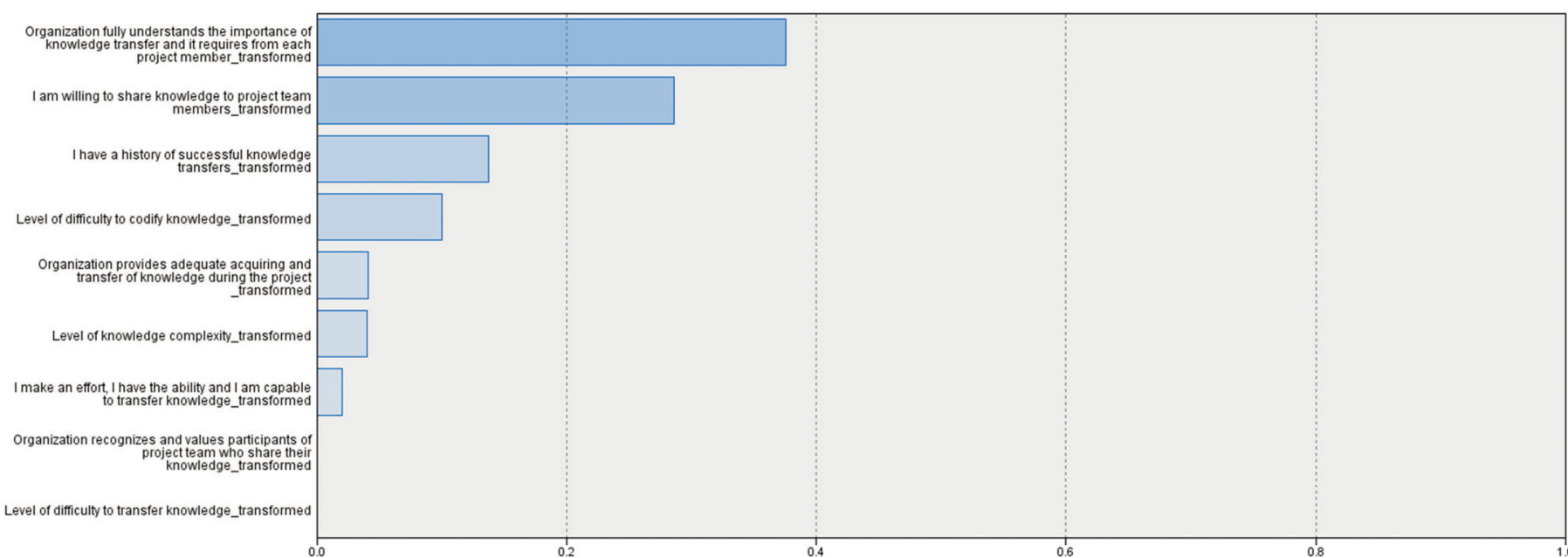


Finally, respondents revealed what are the major barriers to effective knowledge transfer among project team members in the banking sector of Serbia. The results are shown in Table 7.

Table 7: The major barriers for effective knowledge transfer

\begin{tabular}{|l|c|c|}
\hline \multicolumn{1}{|c|}{ The major barriers for effective knowledge transfer } & N & Percent \\
\hline Lack of time due to high pressure of deadlines and project activities & 18 & $33 \%$ \\
Organizational culture & 12 & $22 \%$ \\
Managerial style & 9 & $17 \%$ \\
Not enough capabilities to effectively transfer knowledge & 8 & $15 \%$ \\
Organization does not pursue knowledge transfer & 4 & $7 \%$ \\
Not enough trust & 3 & $\mathbf{6 \%}$ \\
\hline Total & $\mathbf{5 4}$ & $\mathbf{1 0 0 \%}$ \\
\hline
\end{tabular}

Source: Authors

\begin{abstract}
Respondents are of the opinion that the major barrier for knowledge transfer effectiveness lies in the lack of time due to high pressure of deadlines and project activities $(\mathrm{N}=18)$, followed by organizational culture $(\mathrm{N}=12)$. Nine respondents answer that managerial style plays an important role in regard to this phenomenon, while eight participants are of an opinion that the lack of capabilities to effectively transfer knowledge is an important barrier for its success. The smallest number of participants believe that the organization does not pursue knowledge transfer $(\mathrm{N}=4)$. Finally, having no trust in sharing knowledge is viewed as one of the limitations from three respondents included in the study.
\end{abstract}

Taking into account that banks in Serbia are characterized by dominant functional organizational structure in which knowledge is acquired and stored in well-established departments and branches and the fact that it is one of the most disruptive industries nowadays, knowledge transformation among project team members is low. Moreover, very dynamic circumstances, project complexity and tight deadlines create new challenges when knowledge transfer effectiveness is in question. Accordingly, the research results show that organizational understanding, valuing and adequate support for knowledge acquisition and transfer represent significant indicators for knowledge transfer success within project teams in the banking industry of Serbia. Besides, individual readiness, efforts, capabilities and history of successful knowledge transfer play an important role in knowledge transformation success. Finally, regression analysis output disclosed that all observed aspects, i.e., characteristics of knowledge transfer, individual and organizational aspects, represent significant simultaneous predictors for knowledge transfer success among project teams in the banking sector of Serbia.

\title{
Conslusion
}

The fourth industrial revolution, the disruptive innovations and influential external forces such as strong competition, frequent structural, regulatory, technological and customers' requirements changes, along with the economic crisis have imposed serious challenges to the banking industry nowadays. These critical influences have accelerated varied classes of changes, implying substantial increase in the number of projects and their complexity. In addition to this, the temporary nature of projects and tight deadlines, along with all related factors, create an intense challenge and significant concern to all stakeholder groups when effective knowledge transfer is in question.

Knowledge acquiring, using and sharing are widely recognized as a key component to project efficiency, effectiveness and overall project and organizational performances. Despite its relevance, poor project outcomes are evidenced. Yet, little is known about effects of knowledge transfer in banking. Accordingly, this study set out to research the effectiveness of knowledge transfer among project team members in banking, as one of the most digitally disrupted industries nowadays. To this end, this paper opted for a survey research method using an internet-based questionnaire as a survey instrument. The sampling frame consisted of experts who had one of the three conventional roles in a project team, i.e., leader, member or contributor. Of the total invited experts to participate in the survey, 54 completed the questionnaire, yielding a response rate of $36 \%$.

The research results show that knowledge transfer is at a low level of effectiveness among project team members in the banking sector of Serbia. Also, knowledge complexity and difficulty to codify knowledge linearly increase difficulty to transfer knowledge among project team members in banks in Serbia and the same time decrease the success of knowledge transfer. On the other hand, organizational understanding, valuing and adequate support to knowledge acquisition and 
transfer are in a positive correlation with effective knowledge transfer among project teams in the banks that operate in Serbia. Similarly, individual willingness, given efforts, ability and a history of successful knowledge transfer are in an uphill relationship with knowledge transfer success among project teams. The regression analysis output disclosed that all observed aspects, i.e., characteristics of knowledge transfer, individual and organizational aspects represent significant simultaneous predictors of knowledge transfer success among project teams in the banking sector of Serbia. The results are significant and the hypotheses are supported.

Moreover, we have analyzed coefficients for each predictor in the regression model to find out the most and the least important predictors for knowledge transfer success. Among all constant variables in the construct, the most important predictor refers to organizational understanding of knowledge transfer importance and organizational requirement for knowledge transfer from each project team member. Yet, the least important predictor of an effective knowledge transfer is knowledge transfer difficulty.

Finally, respondents included in the study revealed the major barriers to knowledge transfer effectiveness. Based on the results, the biggest limitation lies in lack of time due to high pressure of deadlines and project activities, organizational culture and managerial style. These results further indicate that digitally disrupted organizations should take into account new approaches, principles and measures with respect to project and resources planning, culture and managerial style for further development of knowledge transfer towards its effectiveness between project team members.

The study has some limitations that require further research. First, data were collected with a self-administered questionnaire based on the Internet that reflects subjectivity of answers which might cause an underrating or overrating of results. Hence, future research should conduct qualitative studies to create potential to obtain a deeper understanding of factors that disrupt knowledge transfer effectiveness between project team members in digitally disrupted organizations. Secondly, this study was focused only on data collection from one country and a single industry, i.e., the banking industry of Serbia. Thus future research should incorporate perspectives of project team members from other digitally disrupted industries in Serbia. Also, future research should include cross-cultural exploration to further examine the similarities and differences across the Balkans, a poorly researched region with regard to effectiveness of knowledge transfer success among project teams.

Despite its limitation, the study can contribute both to theoreticians and practitioners in two important ways. First, the paper contributes to the project management theory, knowledge management theory and organizational behaviour theory by extending the literature with findings in regard to this phenomenon. Also, the paper contributes to enriching the literature on knowledge transfer between project teams in an industry's, country's and regional contexts that has been insufficiently researched so far. Second, knowledge transfer contributes to the project and overall organizational performances. Thus, by focusing on this phenomenon, this paper contributes to project managers, strategic managers and policy makers by addressing the gap between importance of knowledge transfer, in one hand, and poor project outcomes on the other.

\section{REFERENCES}

[1] Ajmal. M. M.. \& Koskinen. K. U. (2008). Knowledge transfer in project-based organizations: an organizational culture perspective. Project Management Journal. 39(1). 7-15. DOI: 10.1002/pmj.20031

[2] Alavi. M.. \& Leidner. D. E. (2001). Knowledge management and knowledge management systems: Conceptual foundations and research issues. MIS quarterly. 107-136. Retrieved from http://www.cs.unibo.it/ gaspari/www/teaching/14_KM_KMsystems_Alavi_MISQ.pdf

[3] Argote. L.. \& Ingram. P. (2000). Knowledge transfer: A basis for competitive advantage in firms. Organizational behavior and human decision processes. 82(1). 150-169. DOI:10.1006/obhd.2000.2893

[4] Bakker. R. M.. Cambre. B.. Korlaar. L.. \& Raab. J. (2011). Managing the project learning paradox: A settheoretic approach toward project knowledge transfer. International Journal of Project Management. 29(5). 494-503. DOI:10.1016/j.jproman.2010.06.002

[5] Barisitz. S.. \& Gardo. S. (2008). Financial Sector Development in Serbia: Closing Ranks with Peers. Focus on European Economic Integration. 2(08). 94-119. Retrieved from http://www.policycafe.rs/documents/financial/research-and-publications/financial-sector-developmentin-serbia/financial-sector-development-in-serbia.pdf

[6] Beesley. L. (2004). Multi-level complexity in the management of knowledge networks. Journal of Knowledge Management. 8(3). 71-100. DOI:10.1108/13673270410541051

[7] Bloch. M.. Blumberg. S.. \& Laartz. J. (2012). Delivering large-scale IT projects on time. on budget. and on value. Harvard Business Review. 1-7. Retrieved from https://www.berendt-partner.de/wpcontent/uploads/2014/11/MOBT_27_Delivering_large-scale_IT_projects_on_time_budget_and_value.pdf 
[8] Broadley C. Champion K. Johnson MP \& McHattie L. (2016). From Participation to Collaboration: Reflections on the Co-Creation of Innovative Business Ideas In: Lloyd P. Bohemia E (ed.) Proceedings of DRS 2016: The 50th Anniversary DRS Conference 2016. Future-Focused Thinking. Volume 5. London: Design Research Society. DRS2016: Design Research Society 50th Anniversary Conference. 27.6.2016 - 30.6.2017. Brighton. pp. 1739-1758.

[9] Cacciatori. E.. Tamoschus. D.. \& Grabher. G. (2012). Knowledge transfer across projects: Codification in creative. high-tech and engineering industries. Management Learning. 43(3). 309-331. DOI:10.1177/1350507611426240

[10] Cowan. R.. David. P. A.. \& Foray. D. (2000). The explicit economics of knowledge codification and tacitness. Industrial and corporate change. 9(2). 211-253. DOI:10.1093/icc/9.2.211

[11] Crawford. L.. \& Nahmias. A. H. (2010). Competencies for managing change. International journal of project management. 28(4). 405-412. DOI:10.1016/j.ijproman.2010.01.015

[12] De Long. D. W.. \& Fahey. L. (2000). Diagnosing cultural barriers to knowledge management. The Academy of management executive. 14(4). 113-127. DOI: 10.5465/AME.2000.3979820

[13] Drucker. F. P. (1993). Post-capitalist society. New York: Harper Paperbacks.

[14] Edmondson. A. C.. \& Harvey. J. F. (2018). Cross-boundary teaming for innovation: Integrating research on teams and knowledge in organizations. Human Resource Management Review. 28(4). 347-360. DOI:10.1016/j.hrmr.2017.03.002

[15] Gann. D. M.. \& Salter. A. (1998). Learning and innovation management in project-based. serviceenhanced firms. International Journal of Innovation Management. 2(04). 431-454. DOI:10.1142/S1363919698000195

[16] Haldin-Herrgard. T. (2000). Difficulties in diffusion of tacit knowledge in organizations. Journal of Intellectual capital. 1(4). 357-365. DOI:10.1108/14691930010359252

[17] Howlett. R. J.. Gabrys. B.. Musial-Gabrys. K.. \& Roach. J. (Eds.). (2011). Innovation Through Knowledge Transfer. Springer Berlin Heidelberg

[18] Huang. Y. C.. \& Chin. Y. C. (2018). Transforming collective knowledge into team intelligence: the role of collective teaching. Journal of Knowledge Management. 22(6). pp. 1243-1263. DOI:10.1108/JKM-032017-0106

[19] Kirchner. K.. \& Cudanov. M. (2011). The influence of collaborative Web on knowledge management. organizational structure and culture in knowledge-intensive companies. In Business organizations and collaborative web: Practices. strategies and patterns (pp. 184-201). IGI Global. DOI: 10.4018/978-1-60960-581-0.ch012

[20] Ko. D. G.. Kirsch. L. J.. \& King. W. R. (2005). Antecedents of knowledge transfer from consultants to clients in enterprise system implementations. MIS quarterly. 59-85. DOI: 10.2307/25148668

[21] Lewis. K.. Lange. D.. \& Gillis. L. (2005). Transactive memory systems. learning. and learning transfer. Organization Science. 16(6). 581-598. DOI:10.1287/orsc.1050.0143

[22] Markus. M. L. (2004). Technochange management: using IT to drive organizational change. Journal of Information technology. 19(1). 4-20. DOI:10.1057/palgrave.jit.2000002

[23] Markus. M. L.. \& Benjamin. R. I. (1996). Change agentry-the next IS frontier. Mis Quarterly. 385-407. DOI: $10.2307 / 249561$

[24] Mehta. N.. Hall. D.. \& Byrd. T. (2014). Information technology and knowledge in software development teams: The role of project uncertainty. Information \& Management. 51(4). 417-429. DOI:10.1016/j.im.2014.02.007

[25] Naftanaila. I. (2010). Factors affecting knowledge transfer in project environments. Review of International Comparative Management. 11(5). 834-840. Retrieved from http://www.rmci.ase.ro/no11vol5/06.pdf

[26] NBS.(2016). Financial statements. [Online] Retrieved from https://nbs.rs/internet/english/50/50_5.html.

[27] Park. C.. Im. G.. \& Keil. M. (2008). Overcoming the mum effect in IT project reporting: Impacts of fault responsibility and time urgency. Journal of the Association for Information Systems. 9(7). 409-431. Retrieved from https://pdfs.semanticscholar.org/97dc/86f33ff79c8f3a76093d60349122085b5337.pdf

[28] Peppard. J.. Ward. J.. \& Daniel. E. (2007). Managing the realization of business benefits from IT investments. MIS Quarterly Executive. 6(1). 1-11. Retrieved from http://misqe.org/ojs2/index.php/misqe/article/viewFile/120/115

[29] Prieto-Pastor. I.. Martin-Perez. V.. \& Martín-Cruz. N. (2018). Social capital. knowledge integration and learning in project-based organizations: a CEO-based study. Journal of Knowledge Management. 22(8). pp. 1803-1825. DOI:10.1108/JKM-05-2017-0210

[30] Prusak. L. (2015). Capturing the Value of Project Management Through Knowledge Transfer. In Project management Institute. Retrieved from https://www.pmi.org//media/pmi/documents/public/pdf/learning/thought-leadership/pulse/capture-value-knowledge-transf er.pdf?sc_lang_temp=en 
[31] Rivkin. J. W. (2001). Reproducing knowledge: Replication without imitation at moderate complexity. Organization Science. 12(3). 274-293. DOI:10.1287/orsc.12.3.274.10106

[32] Saris. W.E.. \& Gallhofer. I.N. (2014). Design. evaluation. and analysis of questionnaires for survey research (2nd ed.). New York: John Wiley \& Sons

[33] Snider. K. F.. \& Nissen. M. E. (2003). Beyond the body of knowledge: A knowledge-flow approach to project management theory and practice. Project Management Journal. 34(2). 4-12. Retrieved from https://www.researchgate.net/publication/288610000_Beyond_the_body_of_knowledge_A_knowledgeflow_approach_to_project_management_theory_and_practice

[34] Sokic. A. (2015). Cost efficiency of the banking industry and unilateral euroisation: A stochastic frontier approach in Serbia and Montenegro. Economic Systems. 39(3). 541-551. DOI:10.1016/j.ecosys.2015.01.006

[35] Stevens. M. J.. \& Campion. M. A. (1994). The knowledge. skill. and ability requirements for teamwork: Implications for human resource management. Journal of management. 20(2). 503-530. Retrieved from http://www.krannert.purdue.edu/faculty/campionm/Knowledge_Skill_Ability.pdf

[36] Szulanski. G.. Ringov. D.. \& Jensen. R. J. (2016). Overcoming stickiness: How the timing of knowledge transfer methods affects transfer difficulty. Organization Science. 27(2). 304-322. DOI:10.1287/orsc.2016.1049

[37] Teerajetgul. W.. Chareonngam. C.. \& Wethyavivorn. P. (2009). Key knowledge factors in Thai construction practice. International Journal of Project Management. 27(8). 833-839. DOI:10.1016/j.ijproman.2009.02.008

[38] The Standish Group International (2013). Chaos Manifesto. 2013. Retrieved from: http://versionone.com/assets/img/files/ChaosManifesto2013.pdf

[39] Todorovic. M. L.. Petrovic. D. Č.. Mihić. M. M.. Obradovic. V. L.. \& Bushuyev. S. D. (2015). Project success analysis framework: A knowledge-based approach in project management. International Journal of Project Management. 33(4). 772-783. DOI:10.1016/j.ijproman.2014.10.009

[40] Tornjanski. V.. Knezevic. S.. \& Delibasic. B. (2017). A CRM Performance Measurement in Banking Using Integrated BSC and Customized ANP-BOCR Approach. Management:Journal Of Sustainable Business And Management Solutions In Emerging Economies. 22(1). 71-85. DOI:10.7595/management.fon.2017.0004

[41] Tornjanski. V.. Marinković. S.. \& Jancic. Ž. (2017a). Towards Sustainability: Effective Operations Strategies. Quality Management and Operational Excellence in Banking. Amfiteatru Economic. 19(44). 79-94. Retrieved from http://hdl.handle.net/10419/169058

[42] Turner. J. R.. Grude. K. V.. \& Thurloway. L. (Eds.). (1996). The project manager as change agent: leadership. influence and negotiation. McGraw-Hill.

[43] Turner. J. R.. \& Muller. R. (2003). On the nature of the project as a temporary organization. International journal of project management. 21(1). 1-8. DOI: 10.1016/S0263-7863(02)00020-0

[44] Zhao. D.. Zuo. M.. \& Deng. X. N. (2015). Examining the factors influencing cross-project knowledge transfer: An empirical study of IT services firms in China. International Journal of Project Management. 33(2). 325-340. DOI:10.1016/j.ijproman.2014.05.003

Received: 2018-09-06

Revisions requested: 2018-10-19

Revised: 2018-10-21

Accepted: 2018-12-17

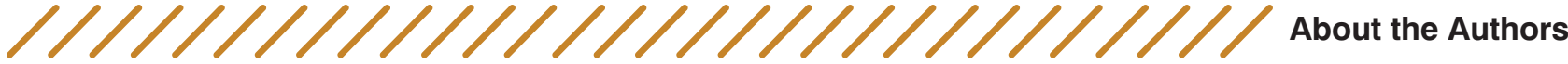

Vesna Tornjanski
University of Belgrade. Faculty of Organizational Sciences. Serbia
e-mail: vtornjanski@gmail.com

Vesna Tornjanski is a PhD candidate at the University of Belgrade - Faculty of Organizational Sciences, Serbia. She works at Eurobank, a.d. Belgrade. Her interests lie in the area of organizational development, service design and business excellence, innovation and technology management and business decision-making. Her research profile is available at: https://www.researchgate.net/profile/Vesna_Tornjansk

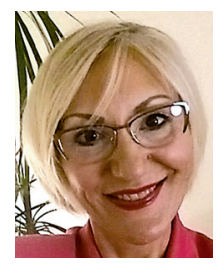




\section{Dejan Petrović}

University of Belgrade, Faculty of Organizational Sciences. Serbia

e-mail: petrovic.dejan@fon.bg.ac.rs

Dejan Petrović, PhD, is a full professor at the Faculty of Organizational Sciences, University of Belgrade, Department of Management and specialized management disciplines. He is also a visiting professor at several universities in the country and abroad. His research interests include management, project management, strategic management, project appraisal and change management. He has been a consultant for a wide variety of public and private organizations and he has published books and articles in refereed journals.

Sandra Nešić

Singidunum University, Faculty of Media and Communications, Serbia e-mail: sandra.nesic@fmk.edu.rs

Dr Sandra Nesic is an Associate Professor at the Faculty of Media and Communications at the Singidunum University, teaching courses on Startup and Entrepreneurship and

Management in the digital age. Dr Nesic published a number of articles in academic journals and co-authored a textbook on Corporate Finance (2010) and on the Modern theories of management: schools and new approaches (2014).

She also holds the position of Program Director at the Center for technoogy entrepreneurship development and innovation - ICT Hub, where her job is to develop and manage programme activities related to entrepreneurial education, startup ecosystem development and corporate innovation. Within the ICT Hub, she developed and is directing an Innovation Management Academy. 